ISSN: 0213-2079 - ISSN electrónico: 2386-3889

DOI: https://doi.org/10.14201/shhmo20173925374

\title{
LA POLÍTICA REAL Y EL TRASLADO DEL CONSULADO EN TIEMPOS DEL RÉGIMEN ANTIGUO
}

\section{Royal Policy and the Transfer ot the Consulado under the Old Regime}

\author{
Allan J. KUETHE \\ Texas Tech University \\ Correo-e: allan.j.kuethe@ttu.edu
}

RESUMEN: El abrupto traslado de la Casa de la Contratación y del Consulado de Cargadores a Indias de Sevilla a Cádiz en 1717 dio lugar al comienzo de una lucha política entre las dos ciudades que no sería completamente resuelta hasta que el absolutismo ilustrado del marqués de la Ensenada impuso su voluntad. Esta lucha fue testigo de la política del Antiguo Régimen en sus mejores y en sus peores aspectos. Este trabajo analiza las varias manifestaciones de esta competición, así como los amplios escenarios en que tuvieron lugar. Aunque el nuevo absolutismo apareció primero con el Abad Alberoni en el traslado original y después con la afirmación del duque de Riperdá, con la mano de la reina Isabel bajo la superficie, la cultura tradicional de consulta y compromiso eventualmente emergió y permitió a Sevilla retener poderes importantes hasta mucho después. Entonces, en una nueva era con prioridades diferentes, profundamente influidas por la llegada de la Guerra del Asiento, el absolutismo real personificado por Ensenada y sus predecesores inmediatos quitarían a Sevilla los derechos que le quedaban y por fin completarían el traslado que había comenzado más de veintiséis años antes.

Palabras clave: Absolutismo ilustrado; Alberoni; Casa de la Contratación; Consulado; Felipe V; Grimaldo; Isabel; Luis I; Miraval; Patiño; Pez; Riperdá. 
ABSTRACT: The abrupt transfer of the Casa de la Contratacion and the Consulado de Cargadores a Indias from Seville to Cádiz in 1717 opened a political struggle between the two cities that would not be completely resolved until the enlightened absolutism of the Marqués de la Ensenada imposed its will. This struggle witnessed old regime politics at both their best and their worst. The present work seeks to analyze the several manifestations of this competition as well as the broader settings in which they occurred. While the new absolutism first appeared through the abad Alberoni in the original transfer and again through its affirmation by the duque de Ripperdá, with the hand of Queen Isabel not far beneath the surface, the traditional culture of consultation and compromise would eventually emerge and permit Seville to retain important powers until much later. Then, in a new era with much different priorities, which were heavily influenced by the coming of the War of the Asiento, royal absolutism as personified by Ensenada and his immediate predecessors would strip Sevilla of its remaining rights and at long last complete the transfer that had begun over twenty-six years before.

Key words: Alberoni; Casa de la Contratación; Consulado; Enlightened Absolutism; Grimaldo; Isabel; Louis I; Miraval; Patiño; Pez; Philip V; Riperdá.

El año 2017 marca el tricentenario del primer acto en el histórico traslado del Consulado de Cargadores a Indias de Sevilla a Cádiz. No sería el último. Antes de que el proceso hubiera terminado completamente, pasarían más de veintiséis años. El Real Decreto de 8 de mayo, un paso adelante reformista, fue el primer tiro en lo que sería una clásica lucha dentro del marco de la política dieciochesca, enfrentando el brusco impulso modernizador a la prevalente tradicional cultura del momento ${ }^{1}$. Los sucesos que siguieron proveen una fascinante vista de la monarquía del Antiguo Régimen en ambos su mejor y su peor aspecto. El presente ensayo trata de elucidar la lucha del traslado y así enfocar con más claridad la transformación que en realidad tuvo lugar.

\section{El traslado}

Es indispensable revisar el cómo y el porqué del real decreto. Las causas a lo largo del tiempo son evidentes. Como se sabe por las exhaustivas investigaciones de Manuel Ravina Martín, Manuel Bustos Rodríguez y Ana Crespo Solana entre

1. Real decreto, Segovia, 8 de mayo de 1717, Archivo General de Indias [en adelante AGI], Indiferente General [en adelante IG], leg. 2039 
otros, las mejores facilidades portuarias en el Atántico, con la capacidad de servir las naves más grandes de los años recientes, le daba ventaja a Cádiz sobre el puerto interior de Sevilla en el Río Guadalquivir². Además, habían aparecido indicios de que la desembocadura del río mostraba efectos de la erosión de los campos vecinos. Dadas estas realidades, para 1680 Cádiz se había convertido en la cabecera para las flotas del Consulado entre España y América ${ }^{3}$. Pero la élite que manejaba el comercio prefería vivir en la sofisticada Sevilla, cerca de sus inversiones en tierra y negocios en vez de en un puerto marino poco desarrollado. Y se podía argüir que las facilidades portuarias de Cádiz facilitarían el contrabando en contraste al entorno relativamente cerrado de Sevilla. Es así que fuerzas poderosas estimaban como esencial anclar el lugar de ambos, el Consulado, que manejaba el comercio americano, y la Casa de la Contratación, que lo supervisaba, en la capital andaluza. Otros que buscaban facilitar y mejorar la competición del comercio legal colonial, junto con intereses extranjeros que querían accesos más fáciles, si bien a veces ilícitos, trabajaban en favor del traslado.

Pero había mucho más. Como solía a menudo ocurrir en esa época, el asunto no se resolvería en términos de su propio mérito, al menos no al principio. El catalizador para cambiar la situación fue el Abad Julio Alberoni, el favorito italiano de la reina Isabel de Parma, segunda esposa de Felipe V. Como bien se sabe, los monarcas compartían un fuerte deseo de recuperar los territorios italianos perdidos bajo los tratados de Utrecht, e Isabel tenía su propio derecho a tierras en Italia. Estas consideraciones causaron la captura de Cerdeña en agosto de 1717 y de Sicilia el siguiente junio. Actuando para preservar el acuerdo de Utrecht y salvaguardar sus propios intereses, los ingleses destruyeron la armada española en el Cabo Passaro, cerca de Sicilia, en agosto de 1718, y un nuevo conflicto hizo erupción meses más tarde. Este conflicto se vino a llamar la Guerra de la Cuádruple Alianza, en la que los franceses, el emperador y el rey de Saboya se unieron a los ingleses ${ }^{4}$.

Durante las preparaciones para las capturas en Italia, cuando casi por magia reunió una armada, Alberoni unió varias fuerzas navales españolas bajo un solo mando, la Intendencia de Marina, poniéndola a cargo de su protegido, José Patiño.

2. Por ejemplo, véanse Ravina Martín, M. (intro.): El pleito de Cádiz Sevilla por la Casa de la Contratación: memorial de Fco. Manuel Herrera 1726... Cádiz, 1984; Crespo Solana, A.: La Casa de la Contratación y la Intendencia General de Marina en Cádiz. Cádiz, 1996; Bustos Rodríguez, M.: Cádiz en el sistema atlántico: la ciudad, sus comerciantes y la actividad mercantil (1650-1830). Cádiz, 2005.

3. García Fuentes, L.: El comercio español con América, 1650-1700. Sevilla, 1980, pp. 63-65.

4. Estos asuntos los he tratado con Kenneth J. Andrien en The Spanish Atlantic World in the Eighteenth Century: War and the Bourbon Reforms, 1713-1796. Cambridge, 2014, pp. 57-61. 
Al poner las fuerzas navales mediterráneas y americanas bajo una administración común, Alberoni así mismo unió la Casa de la Contratación a la Intendencia 5 . Este adelanto halló expresión en la Real Cédula de 28 de enero de 1717, siendo precursora del histórico decreto de mayo ${ }^{6}$. El arreglo combinaba institucionalmente ambas, la Casa y la Intendencia, con Patiño asumiendo el título de intendente general de marina, superintendente del Reino de Sevilla y presidente de la Casa de la Contratación. Como la cédula aclaraba «los Diputados del Consulado deberán así mismo pasar a residir» en Cádiz. De esta manera, aunque otros profundos factores de largo alcance estaban presentes, la causa inmediata para el traslado fue militar, al acompañar el Consulado a la Casa a Cádiz.

Es importante notar, sin embargo, que a medida que efectuaba el traslado Patiño, en una importante concesión a Sevilla, le asignaba a esta provisionalmente veinte de los treinta electores para sus elecciones anuales ${ }^{7}$. El resto fue a Cádiz, pero con la estipulación de que el prior y el primer cónsul de dos, habrían de ser sevillanos. Es claro que Cádiz protestó de este arreglo queriendo controlar todo, pero el interludio de Alberoni no estaba destinado a durar mucho ${ }^{8}$.

Para la corte de Madrid, Alberoni era un forastero intruso. Habiendo llegado a España durante la Guerra de Sucesión con el ejército francés del duque de Vendome, se las arregló para ganar el favor de María Luisa, la primera esposa de Felipe V; y a su muerte, convenció a Felipe y a los poderes a su alrededor de que un excelente reemplazo lo sería Isabel, una princesa de Parma que, es de notar, era de su propio país. En muy corto tiempo el Abad Alberoni también se ganó el favor de la nueva reina, y cuando Felipe cayó presa de una profunda depresión, siendo de facto primer ministro al asumir ella la autoridad real. En efecto un gran número de italianos pronto reemplazó la extensa e influyente clique francesa que había infestado la corte durante los primeros años del reino de Felipe ${ }^{9}$. Uno

5. Idem, p. 74. Una intendencia de marina había existido en alguna forma desde fecha tan temprana como 1715. Pérez-Mallaína Bueno, P. E.: La política española en el Atlántico, 1700-1715. Sevilla, 1982, pp. 346.

6. Una copia de la cédula se halla en Fernández Duro, C.: Armada española desde la unión de los Reinos de Castilla y Aragón, IV. Madrid, 1972-1973, pp. 222-23.

7. Heredia Herrera, A.: Sevilla y los hombres del comercio (1700-1800). Sevilla, 1989, pp. 127-28.

8. GIRARD, A.: La rivalité commerciale et maritime entre Séville et Cadix jusqu'a la fin du XVIII siècle. París y Burdeos, 1932, p. 83.

9. He tratado la influencia italiana con más detalle en «La política exterior de Felipe V y el primer reformismo», en Lavallé, B. (redactor): El primer siglo XVIII en Hispanoamérica. Toulouse, 2012, pp. 30-32. 
de ellos era José Patiño, nacido en Milán e hijo de una noble dama italiana y un militar gallego, y quien, a su vez, había casado con una italiana ${ }^{10}$.

Es importante comprender que la costumbre limitaba la influencia directa de Isabel porque ella no era la madre del príncipe de Asturias. Dos hijos de su predecesora, María Luisa, habían sobrevivido, Luis y Fernando, quienes se hallaban delante de su hijo Carlos como herederos al trono. Para llevar a cabo el despacho de los asuntos de estado, ella se sentaba al lado de Felipe, tomando la palabra la mayor parte del tiempo; pero ella animaba a Felipe a dar muestra de su consentimiento. En la correspondencia con la corte francesa, ella de costumbre escribía al dorso de los mensajes que su marido garabateaba ${ }^{11}$. Y, por supuesto, ella trabajaba por medio de favoritos, a menudo extranjeros, para avanzar su agenda. Alberoni era el primero.

En este momento, se debe notar que un poderoso hijo de Cádiz, el almirante Andrés de Pez, fue nombrado gobernador del Consejo de Indias. Él, junto con Patiño, había hecho mucho para facilitar el traslado de Isabel de Parma a España, y ella no se había olvidado de ese invaluable servicio ${ }^{12}$. Este venerable gaditano, quien por tanto tiempo había trabajado en favor de su ciudad natal, facilitó el curso del decreto de mayo por el Consejo sin consulta formal ni otras complicaciones. Bajo circunstancias normales, una innovación de esta importancia hubiera ocasionado extenso estudio, durante el cual las partes vinculadas habrían podido hacerse oír. Pero el proceso llego al Consejo "para su inteligencia», no su contribución ${ }^{13}$.

\section{EL REVERSO}

La alegría de Cádiz duró poco. El traslado dependía de Alberoni y sus aliados, que eran pocos en número y quienes, más allá del apoyo de la reina, no tenían peso político. Él era solo un forastero, y sus bruscos métodos eran vistos por muchos como autoritarios y, de hecho, despóticos. A medida que consolidaba

10. Béthencourt Massieu, A.: Patiño en la política internacional de Felipe V. Valladolid, 1954, p. 13.

11. Con Kenneth J. Andrien he tratado el papel de Isabel con más detalle en The Spanish Atlantic World, p. 77.

12. Castro, A. de: Vida del Almirante D. Andrés de Pes, ministro de marina. Cádiz, 1879, pp. 20, 25-41.

13. El Real Decreto del 8 de mayo de 1717, dado en Segovia, vino por la mesa de Miguel Fernández Durán, del Secretario de Guerra, quien asumía las responsabilidades de aquella parte de Marina e Indias después de su supresión en 1715. Castellano, J. L.: Gobierno y poder en la España del siglo XVIII. Granada, 2006, pp. 77-78. El expediente para el real decreto se encuentra en AGI, IG, leg. 2039. 
sus poderes durante los años de 1715 a 1717, suprimió la Secretaría de Indias y humilló a Bernardo Tinajero, su primer ministro; puso las otras tres secretarías bajo su supervisión personal, y limitó la independencia del Consejo de Indias ${ }^{14}$. Mientras las cosas iban bien, tenía el apoyo de los monarcas. En efecto, después de la captura de Cerdeña, Isabel intervino personalmente con el Papa para asegurarle al advenedizo su ascenso a Cardenal ${ }^{15}$. Pero la falta de apoyo en la corte aparte del de la familia real era bien visible. Como observó el embajador francés Saint Aignan, «El Abad Alberoni nunca hallará apoyo entre los españoles...Y Yo no dudo que aquellos que alimentan esperanzas de hacerse dueños del gobierno le sacrificarían alegremente» ${ }^{16}$.

La seria humillación en la Guerra de la Cuádruple Alianza pronto puso fin a la influencia de Alberoni. Ante una fuerte protesta contra el valido, doméstica y extranjera, Felipe no tuvo más remedio que exiliar al favorito de su esposa y hacer la paz con sus poderosos adversarios. La agenda reformista que el italiano había adelantado pronto se derrumbó y juna violenta reacción hacia todo lo que él había aprobado se hizo sentir en todo el reino! Esta reacción incluía, entre otras cosas, la anulación de sus experimentos con un sistema de intendentes para España, un monopolio de tabaco en Cuba y un virreinato en Nueva Granada ${ }^{17}$. Dentro de este contexto fue posible para Sevilla conseguir la anulación del muy aborrecido traslado del Consulado a Cádiz.

El traslado de 1717 había hallado al Consulado de Sevilla en un estado económico y político debilitado. El gremio había sido una casa dividida desde por lo menos el fin del siglo. Durante la Guerra de Sucesión, intrusos franceses en la corte hallaron en Bernardo Tinajero, el líder del bando disidente del Consulado, un instrumento útil para su agenda. Antes de que todo llegara a su fin, los cónsules y los priores de los años 1689 a 1705 acabaron en prisión, con sus bienes confiscados, en tanto que la corona suspendía los pagos de las libranzas sobre cajas americanas que había usado como colateral para sus inmensos préstamos. En 1709, estos instrumentos fueron retirados de la Real Hacienda. De entonces

14. Para la consolidación de los poderes de Alberoni, véase Kuethe, A. J. y Andrien, K. J.: The Spanish Atlantic World, p. 48.

15. García Cárcel, R.: Felipe $V$ y los españoles: una visión periférica del problema de España. Barcelona, 2002, p. 152.

16. Saint Aignan al rey de Francia, San Lorenzo, 21 de junio de 1717, Archives des Affaires Étrangéres (París): Correspondance Politique Espagne, vol. 258, fols. 90-92.

17. Pietschmann, H.: Las reformas borbónicas y el sistema de intendencias en Nueva España: un estudio político administrativo, trans. por Rolf Roland Meyer Misteli. México, 1996, pp. 51-56; Kuethe, A. J. y Andrien, K. J.: The Spanish Atlantic World, pp. 84-94. 
en adelante, «legítimos acreedores», o sea, los amigos de Tinajero, recibieron algo pero la mayoría de los otros, nada. ${ }^{18}$

Para agravar la situación, pérdidas mayores ocurrieron en el área de transporte transatlántico. Aparte de las serias interrupciones comerciales surgidas de la guerra, se perdieron los galeones de José Fernández de Santillán en 1706 y, en 1715, la flota de Juan de Ubilla. Es más, al principio de la guerra, los ingleses habían forzado a la flota de Manuel Velasco a refugiarse en el puerto de Vigo, donde procedieron a destruirla. Aunque mucho del tesoro se rescató, aun cuando la flota se consumía en llamas, la corona logró apropiarse de la mayor parte de esos dineros antes de que pudiera llegar a Sevilla. Las libranzas que Madrid concedió para tranquilizar su conciencia en este asunto probaron ser de poco valor inmediato ${ }^{19}$.

En 1714, Tinajero fue nombrado primer secretario del Despacho de Marina e Indias. No obstante, este arreglo cambió abruptamente con la ascensión de Alberoni. Defendiendo las prioridades mediterráneas de la reina, el intruso se deshizo de Tinajero, quien favorecía una orientación atlántica. Aunque Alberoni liberó al sufrido liderato del Consulado, no devolvió las libranzas retiradas a la Real Hacienda en $1709^{20}$. De este modo, la amargamente dividida élite sevillana se halló en una situación económica debilitada cuando la Casa y el Consulado fueron sacados de la ciudad.

Había todavía, es cierto, individuos con fortunas personales considerables, tal como el ilustre sevillano Lope Thous de Monsalve, marqués de Thous, caballero con hábito de la orden de Santiago. Terrateniente con negocios de vino y aceite, poseía suficientes medios para cubrir con regularidad los gastos cotidianos del Consulado durante los años de su crisis económica. Él mismo sirvió de prior los años de 1711,1713 , y de 1715 a $1717^{21}$. Una vez que la amplia reacción contra Alberoni tomó fuerza, individuos como Thous aprovecharon la oportunidad de unirse a las fuerzas anti reformistas que trataban de anular sus obras.

En tanto en la corte, el hombre del momento lo era el marqués de Grimaldo, distinguido magistrado largo tiempo gozando de la confianza de Felipe. Madrileño, de ascendencia italiana lejana, había ascendido gradualmente en la corte en

18. Pérez Mallaína, P. E.: Política naval, pp. 80, 220-24, 127.

19. Kuethe, A. J. y Andrien, K. J.: The Spanish Atlantic World, pp. 75-76.

20. La lucha para recuperar las libranzas continuaba por años. Solicitud de José de Larrarte, apoderado, Consulado de Cádiz, 1735, AGI, IG, leg. 2324.

21. Bustos Rodríguez, M.: «El Consulado de Indias en Cádiz y sus hombres: el cambio de relaciones entre la institución y el cabildo municipal», en Acosta Rodríguez, A., GonzÁlez Rodríguez, A. y Vila Vilar, E.: La Casa de la Contratación y la navegación entre España y las Indias. Sevilla, 2003, pp. 915-16; Heredia Herrera, A.: Sevilla y los hombres, pp. 153-54 y 166-69. 
la Secretaría de Nueva España del Consejo de Indias, donde su padre servía de oficial mayor. Cuando el Despacho Universal fue dividido entre dos secretarios en 1705, Michel Jean Amelot le había nombrado secretario de Guerra y Hacienda ${ }^{22}$. Cuando los secretarios fueron divididos en cuatro nueve años después, el sucedió a Estado, y allí permaneció. Alberoni le había relegado en importancia, pero en ese momento Felipe acudió a su antiguo amigo para arreglar los destrozos acaecidos durante el interludio de Alberoni y de la guerra ${ }^{23}$. Magistrado prudente, de mucho tacto y con inclinaciones conservadoras, procedió de manera consistente con la acostumbrada cultura política para resolver la violenta disputa que había surgido entre Sevilla y Cádiz por los traslados.

El contraste con la conducta del Cardenal Alberoni es en alto grado instructivo. Bajo las presiones impuestas por la probable amenaza de conflicto armado, Alberoni, quien por temperamento era precursor del impaciente absolutismo ilustrado de Ensenada y de Carlos III, había actuado decisivamente, manteniendo al mínimo la habitual consulta y compromiso tan típica de la prevalente cultura heredada de la época Habsburgo. Por contraste, Grimaldo abrazaba la tradición. Aunque con un predeterminado fin en mente, se aseguraba de que todas las partes involucradas tuvieran voz, y procedía con suma deliberación. Los que salían perdiendo tenían así tiempo para adaptarse a la nueva realidad que gradualmente descendía sobre ellos. Una temprana advertencia lo fue el Real Decreto de 6 de diciembre que confirmaba lo que para Cádiz era el muy aborrecido arreglo de la votación diseñado por Patiño durante el traslado inicial ${ }^{24}$.

En respuesta a los clamores de Sevilla, Grimaldo en 1722 dio poder a Luis Miraval y Espínola, gobernador del Consejo de Castilla y aliado político, a formar una junta para decidir la sede adecuada para la Casa de la Contratación y el Consulado. También la dirigiría ${ }^{25}$. Como gobernador del Consejo de Castilla, Miraval parecía el hombre ideal para la tarea. De alto rango, descendía de una distinguida familia de Jerez de la Frontera, por lo que conocía bien la región ${ }^{26}$. Pero Grimaldo seguro que sabía también que Miraval había colaborado años antes con Tinajero

22. Castro, C. de: A la sombra de Felipe V: José Grimaldo, ministro responsable (1703-1726). Madrid, 2004, pp. 126-127.

23. Escudero, J. A.: Los orígenes del Consejo de Ministros en España, I. Madrid, 1979, cap. 3.

24. Girard, A.: La rivalité commerciale, p. 83.

25. Este expediente se encuentra en el Archivo Histórico Nacional [en adelante AHN], Estado, leg. 2093.

26. El fallecido hermano de Miraval, Martín José, había servido con distinción como ministro togado del Consejo de Indias. Burkholder, M. A.: Biographical Dictionary of Councilors of the Indies, 1717-1808. Nueva York, 1986, p. 80. 
y su facción del Consulado ${ }^{27}$. Desde el punto de vista de Sevilla, el jerezano era una elección ideal, y el comité que nombró refleja esa realidad.

En el centro había representantes de los cinco consejos mayores: Castilla, las Indias, Hacienda, la Suprema Inquisición y Órdenes. Otros miembros incluían Andrés de Pez como secretario de Marina e Indias, quien era también todavía gobernador del Consejo de Indias, y José Patiño, como intendente de Marina. A pesar de los inconvenientes asociados con la caída de Alberoni, ambos habían vuelto a su antiguo estado. Miraval también eligió a Francisco Varas y Valdés, brevemente presidente de la Casa e intendente pero ahora un oidor de su audiencia. Durante su servicio, él había hecho varios sondeos del canal de Sanlúcar ${ }^{28}$. Además, Miraval autorizó representaciones de ambas Sevilla y Cádiz. Por último, eligió a Jerónimo de Ustáriz como secretario ${ }^{29}$. Grimaldo, como era de esperar, aprobó el trabajo de Miraval y le ordenó informar a Pez «para que lo tenga entendido y se expidan por su mano [la vía reservada] a quien toca las órdenes convenientes para la formación de la junta» ${ }^{30}$.

En la superficie, el comité de Miraval tenía la apariencia de imparcialidad, incluyendo ambos experiencia y equilibrio, pero en realidad era otra cosa. Los Consejos históricamente habían sido bastiones de la aristocracia, conservadores en carácter. Todavía lo eran ${ }^{31}$. En cuanto a Varas, había cultivado profundas relaciones personales con la élite sevillana durante su servicio con la Casa. Es más, Miraval nombró al influyente marqués de Thous el representante de Sevilla. Thous ya había tenido contacto con Miraval, estaba bien relacionado en la corte, y contaba a Grimaldo entre sus íntimos, así como a su mano derecha, Juan Bautista de Orendain, oficial mayor en la Secretaría de Estado, quien había ido avanzando rápidamente ${ }^{32}$. En cuanto a Cádiz, Miraval dejó a los gaditanos elegir a su propio hombre. Es muy instructivo que el ayuntamiento de Cádiz, obviamente dándose cuenta de que las cosas iban en contra de sus intereses, rehusó nombrar un representante al proceso. Es más, Patiño y Pez, quien obedientemente había procesado el papeleo para formar el comité, trataron ambos de excusarse de tomar parte actual, obviamente esperando evitar una humillación personal. Pero Grimaldo no

27. Pérez Mallaína, P. E: Politica naval, p. 220.

28. Girard, A.: La rivalité commerciale, pp. 82-83.

29. Este proceso he descrito con más detalle en «Traslado del Consulado de Sevilla a Cádiz: nuevas perspectivas», en VILA VIlaR, E. y Kuethe, A. J. (redactores): Relaciones de poder y comercio colonial: nuevas perspectivas. Sevilla, 1999, pp. 66-82.

30. Grimaldo a Miraval, Valsaín, 13 de julio de 1722, AHN, Estado, leg. 2093.

31. Castellano, J. L.: Gobierno y poder, cap. 2.

32. Crespo, A.: La Casa, p. 105; Kuethe, A. J.: «Traslado del Consulado», p. 71. 
lo permitió. Su participación era esencial para mantener las apariencias. En cuanto a Cádiz, el comercio eventualmente seleccionó a Francisco López de Villamili33.

El comité se reunió por primera vez a principios de octubre de 1722 y se reunió a intervalos hasta finales de noviembre. El informe apareció a fines del año. La votación fue tal y como se esperaba con una excepción: Jacinto de Arana, Suprema Inquisición, favorecía el Puerto de Santa María como el sitio mejor. Grimaldo aprobó el trabajo del comité34. De seguro todavía creyendo que su trabajo había sido en vano, Andrés de Pez falleció tres meses después ${ }^{35}$. Cádiz se halló así privada de su más fuerte defensor en el preciso momento en que se enfrentaba a una amarga pérdida política.

Sin embargo, al proceso le faltaba mucho para llegar a su fin. Para buena medida, Grimaldo prudentemente determinó que la navegabilidad del río debía ser comprobada antes de la decisión final de Su Majestad. Asignó esta tarea a Manuel López Pintado, marino distinguido con raíces sevillanas pero de intachable lealtad a la corona. Antes de empezar esa tarea, López insistió en que su nave fuera carenada. Para cuando esto fue completado, el verano ya había llegado y el Guadalquivir se hallaba en su nivel más bajo. Sin embargo, López pudo afirmar que el río era completamente navegable. Presentó su informe el 6 de septiembre de $1723^{36}$. Entonces, tras un proceso de un año que había involucrado respetables magistrados, opiniones expertas, las partes interesadas, así como la opinión de un respetado marino, Grimaldo tenía una base sólida para devolver el Consulado y la Casa a Sevilla.

Solo faltaban detalles administrativos. Estos esencialmente consistían en separar la Casa de la Contratación de la Intendencia de Marina a la que había sido unida. Esta tarea requería nuevas definiciones de cargos, considerable papeleo y la elección y nombramiento del personal adecuado ${ }^{37}$. El Consulado esperaba el resultado de este proceso en Cádiz, pero la victoria de Sevilla parecía segura.

El azar intervino. El 10 de enero de 1724, el rey Felipe sorprendió al mundo al abdicar el trono, dejándolo en manos de su hijo Luis, de diecisiete años. Presa de profunda depresión, el atribulado monarca escapó de Madrid refugiándose en

33. Grimaldo a Miraval, Valsaín, 1 de octubre de 1722, y Patiño a Miraval, Madrid, 2 de octubre de 1722, AHN, Estado, leg. 2093; Ravina Martín, M.: El Pleito, pp. 80-81.

34. Miraval a Grimaldo, Madrid, 29 de noviembre de 1722 y Grimaldo a Miraval, Valsaín, 30 de noviembre de 1722, AHN, Estado, leg. 2093.

35. CASTRO, A. de: Vida del almirante, pp. 92-93.

36. AHN, Estado, leg. 2933. Cádiz acusó a López Pintado de fraude. Ravina Martín, M: El Pleito, pp. 90-91.

37. Crespo, A.: La Casa, p. 49. 
La Granja de San Ildefonso, el encantador palacio que acababa de construir en las montañas del norte. Con él se llevó a Grimaldo pensando usarlo como intermediario a través de quien podría aconsejar al jovenzuelo. Luis I, influido por las voces tradicionalistas de la corte, pronto llegó a creer que el Consulado debía estar en Sevilla, pero Grimaldo no estaba presente para facilitar el asunto. No obstante, el proceso de separar la Casa de la Intendencia continuó si bien lentamente ${ }^{38}$.

El azar intervino una vez más cuando el joven monarca cayó víctima de la viruela y falleció el 31 de agosto después de un corto reino de solamente unos siete meses. La muerte de Luis fue de gran importancia en el drama sobre dónde asentar la sede del Consulado, porque las Cortes trajeron de vuelta al trono a Felipe y con él a Isabel Farnesio. Recordando la agenda de su valido, el Cardenal Alberoni, ella no era amiga de Sevilla, aunque llevaría tiempo para que este factor se hiciera sentir.

En este momento, la restauración de Felipe y su régimen ocasionó más demoras en el proceso, como también el proceso en curso de separar institucionalmente la Casa de la Contratación de la Intendencia de Marina. Durante este interludio, Orendain mantenía la causa de Sevilla en la corte ${ }^{39}$. El tan esperado decreto que devolvía el Consulado y la Casa a Sevilla finalmente llegó el 21 de septiembre de $1725^{40}$. Sevilla, obviamente preparada para la noticia, señaló la ocasión con tres grandes días de celebración, mientras que por la noche luminarias brillaban alegremente en la Casa de Lonja. La ira y la amargura del comercio de Cádiz se puede apreciar en su tersa comunicación al ayuntamiento de Sevilla:

en consecuencia de lo que Vms. nos participan de haber mandado poner tres noches luminarias en la Casa de Lonja, ya todos los ministros de esa diputación, debemos decir, no obstante de hallarse este consulado sin un real en las cajas, para satisfacer éstas y otras indispensables obligaciones, que se ofrecen, se servirán vms. remitirnos razón del importe de la cera, que en dichas tres noches se consumió en la Lonja para que todo el gasto salir en una misma libranza como se ha practicado en semejantes $\operatorname{casos}^{41}$.

Bajo las reglas políticas de costumbre, Sevilla había tenido la ventaja y un respaldo muy habilidoso.

38. Extracto de la resolución, 23 de julio de 1724, AHN, Estado, leg. 2093; Castellano: Gobierno y poder, 92-94.

39. Ravina Martín, M.: El pleito, pp. 102-103.

40. AGI, IG, leg. 2039.

41. El consulado de Cádiz a los diputados de Sevilla, 2 de diciembre de 1725, AGI, Consulados, libro 66. Citado originalmente en Kuethe, A. J.: «El traslado», p. 78. 
Es de asumir que favores monetarios tuvieron parte en esta lucha. La sospecha permaneció viva en la memoria popular, articulada en fecha tan tardía como 1777, de que dineros extranjeros, obtenidos por Alberoni para ayudar a costear sus ambiciosas operaciones italianas, habían facilitado en primer lugar la arriesgada decisión de trasladar la Casa y el Consulado a Cádiz ${ }^{42}$. Es de asumir que más tarde el sevillano marqués de Thous empleó su riqueza ventajosamente. Al menos, como se verá más adelante, Isabel Farnesio pensaba así. Y es probable que otros lo hicieran también. Estas sospechas, sin embargo, son difíciles, probablemente imposibles, de verificar. La sigilosa mano del que utiliza sus poderes monetarios para influenciar la política gubernamental deja poca o ninguna huella para el historiador.

\section{CÁdiz OTRA vez}

Sin embargo, el triunfo de Sevilla duró poco. En la Nochebuena de 1725, justo cuando el proceso de seleccionar pretendientes a las plazas del tribunal de la Contratación llegaba a su fin, un real decreto dejó atónita a Sevilla y alegró a Cádiz anulando el retorno de Cádiz de la Casa de la Contratación y el Consulado ${ }^{43}$ :

El Rey ha resuelto que por ahora y hasta nueva orden, se suspenda la ejecución de las que debieron expedirse en cumplimiento del Decreto de Su Majestad dirigido al Consejo de Indias sobre que el Tribunal de la Casa de la Contratación y el Consulado vuelvan de Cádiz a Sevilla ${ }^{44}$.

Esta orden demolía el trabajo tan cuidadosamente llevado a cabo por Grimaldo y Miraval, dejando al margen a Sevilla fría y cruelmente una vez más.

La revocación de la revocación se asemeja al traslado original en varios aspectos. El poder de Isabel Farnesio resurgió a través de otro favorito, otro extranjero, el duque de Riperdá, quien emitió el decreto. Riperdá, un aventurero holandés, quien había hallado el camino a la corte, atrajo la atención de Alberoni, quien le dio su amistad y le puso a cargo de la real fábrica en Guadalajara. Ni corto ni perezoso, se las arregló para sobrevivir a la caída de su patrón italiano y ganar el favor de la reina. Durante el otoño de 1725, cuando las relaciones de España con la Francia Borbona estaban tensas, ella le despachó junto con Juan Bautista de Orendain, entonces secretario de Hacienda, en una misión de confianza a Viena, donde negoció el Tratado de Viena del 5 de noviembre. Este tratado consiguió,

42. Consulta, Consejo de Indias, 1777, AGI, IG, 2409.

43. Expediente, plazas ... de la Contratación, otoño, 1725, AHN, Estado, leg. 2933.

44. Riperdá al duque de Arión, Madrid, 31 de diciembre de 1725, AGI, IG, leg. 2039. 
por fin, el reconocimiento por parte del emperador de la sucesión borbona y aparentemente abrió la puerta a una alianza dinástica con el matrimonio de Carlos con María Teresa, su primera hija y heredera. Esta ilusión pronto se esfumaría, pero, en ese instante, Riperdá era el hombre del momento, quien, a su retorno funcionaría como de facto primer ministro ${ }^{45}$.

Isabel tenía a su nuevo Alberoni, y él emitió el decreto de diciembre 31. Este mando vino sin advertencia ni consulta. Vino de una áspera y absolutista forma, rara hasta para los reformadores dieciochescos, pero Riperdá no era nada típico. En cuanto al envejecido Grimaldi, este había sido hecho de lado de la misma manera que cuando Alberoni mandaba. El anciano magistrado finalmente sería relevado de su cargo el próximo septiembre ${ }^{46}$.

La pregunta surge en cuanto a los motivos de la reina. El decreto original había venido bajo Alberoni y ese recuerdo de seguro permanecía latente nueve años después. Entonces también, otro favorito, José Patiño, quien había sido responsable de implementar la reforma de 1717, permanecía a la mano. Más allá de estos obvios factores, sin embargo, una vista más profunda de su pensamiento se puede discernir de una misteriosa orden que ha sobrevivido entre los documentos relativos a la controversia. Dirigida a Riperdá, aunque sin firma, es más que probable que fuese la reina la autora de la nota, ya que pocas personas se hubieran atrevido a dirigirse al orgulloso Riperdá en la forma familiar o incluso darle órdenes. Y si no lo hizo personalmente, de seguro que vino desde su círculo íntimo:

Duque, es zierto que vuestra restituzion a sido Plausible tocante a la Suspensión del Comerzio y tribunal a Sevilla porque los ministros que vieron en Justicia eran todos pan y aguados de Miraval y Contra viento i marea siendo más agente que Sevilla lo consiguió de la forma que lo sabras i Orendain fue también agente por varios regalos i el Decreto lo dispuso el diputado de Sevill i lo más sensible es los ministros tan indignos que nombraron a contemplazion de Varas por sus fines particulares i así te digo que nunca combiene que este sea Presidente de la Contratazion sino lejos de acá porque en el Comerzio se a echo rrico (sic) y a Sevilla orse (sic) Duque que le redunda poca utilidad el que vengan tribunales o/no sino a quatro particulares como Varas Tous Pintado i otro tal qual porque en ninguna Ciudad de España defraudan tanto al Rei como en Sevilla esto es los que tienen haziendas pues Como los Coches como no se registran todo lo meten por alto i Mateo Pablo administrador teme a todos después que se a echo poderoso con la administración de la aduana para mandar rreconozer (sic) que a buen seguro que si se registrara suvieran las rentas míralo todo con madurez i pon rremedio (sic) Duque i quita tanto salario i

45. Escudero, J. A.: Los orígenes, p. 84.

46. Lynch, J.: Bourbon Spain, 1700-1808. Oxford, 1989, p. 89. 
Intendentes i tan crecidos sueldos en las Casas de moneda quando por nada estava antes mejor mejor (sic) servido i se aorrava el Rei mil doblones de salarios solo en la Casa de moneda de Sevilla que esto me lo a enseñado la experiencia. Dios te de acierto Duque i te guarde para remedio de la monarchia. Así mismo te prebengo Duque sobre elecciones de Consulado fuera mexor que el Presidente de la Casa propusiese al Consejo los que havian de ser que no el de ver tanto rruido (sic) como ai siempre con parzialidades i todo se hase a contemplación de Tous Diputado de Sevilla quien haviendo sido dueño de los Cónsules de Comerzio desde el tiempo de Tinajero por eso se a echo tan rrico (sic) a costa del pobre Comerzio que solo en los Ministros de Consulado i Contratazion se pagan más de quarenta mill (sic) e[scudos] de sueldo i regalos de Cajones de chocolate i tavaco a los Consejeros de Indias que el Pobre Comerzio esta mui gravado porque quiere Tous Varas i otros porque con esto hazen su negocio i así Duque remediarlo todo i a que asta ahora ha sido todo una desorden ${ }^{47}$.

Es obvio que en esta coyuntura, Sevilla y aquellos cercanos a ella disfrutaban de poco apoyo ¡donde el apoyo era necesario! Sin embargo, Cádiz, temiendo que el asunto no estuviera definitivamente resuelto, redactó en febrero de 1726 otra fuerte defensa de sus méritos ${ }^{48}$.

Los poderes de Riperdá se ampliaron antes de rápidamente disolverse. En febrero, añadió a sus poderes las secretarías de Marina e Indias y de Guerra. Y viendo como rivales a Patiño y a su hermano Baltasar, marqués de Castelar, les asignó misiones diplomáticas para sacarlos de la corte. El astuto intendente, aparentemente consciente de la vulnerabilidad del valido, se hizo a un lado y demoró su partida. La caída de Riperdá vino de súbito, el 14 de mayo, cuando la realidad llegó poco a poco desde Viena, que el aventurero había exagerado su logro diplomático. José Patiño le sucedió en Marina e Indias, pronto añadiendo Hacienda, y en 1730 , Guerra ${ }^{49}$.

La caída del intruso holandés dio lugar al prospecto de que el reverso bajo Riperdá del reverso bajo Grimaldo y Miraval del traslado bajo Alberoni, ¿no pudiera también ser revertido? Pero la posición de Isabel se había reforzado al elevar Felipe a su antiguo favorito, José Patiño, a secretario. También, Felipe se puso tan incapacitado a finales de 1726 que se vio obligado a formalmente confirmar los poderes de gobernadora de Isabel ${ }^{50}$.

47. Carta, sin fecha, AHN, Estado, leg. 2933. Aquí se presenta la carta original sin modificación. Fue citada originalmente en Kuethe, A. J.: «El traslado», pp. 79-80.

48. Ravina Martín, M.: El pleito, pp. 107-108.

49. Escudero, J. A.: Los orígenes, pp. 84, 89-92.

50. Kamen, H.: Philip V of Spain: The King who Reigned Twice. New Haven, 2001, pp. $159-62$. 
En esta coyuntura crítica, Patiño, quien se convertiría en un poderoso instrumento del absolutismo borbón, impuso lo que vino a ser un compromiso práctico, resucitando el arreglo que había hecho en 1718 como intendente de Marina, que fue reafirmado en 1721 y que no agradaba a ninguno de los dos bandos. El aparato administrativo del Consulado permanecería en Cádiz, donde de todas maneras radicaba la cabecera de la flota desde 1680 , pero Sevilla retendría el control político. De los delegados con voto del gremio, veinte serían de Sevilla, diez de Cádiz, con el prior y el primer cónsul siendo siempre sevillanos. Es más, Sevilla retendría, así mismo, una subdelegación de la Casa-Intendencia para adjudicar los problemas que pudieren surgir en su facilidad portuaria y el archivo ${ }^{51}$. Mientras esto era menos de lo que Sevilla anhelaba, la mayoría del gremio permanecería en ella, donde radicaban sus propiedades, negocios y familias. Dada la presente configuración política de la corte, este era probablemente lo más que Sevilla podía obtener bajo las circunstancias. Cádiz retenía la sede, algo que representaba un importante paso adelante. Este práctico compromiso, en el que cada lado recibía algo, si bien menos de lo que deseaba, demuestra las impresionantes habilidades políticas de Patiño, al echar a un lado esa paralizante disputa y dirigir su atención a los enormes problemas a los que la corona se enfrentaba. La fórmula que había diseñado -mezcla de la vieja y de la nueva política- perduraría durante su vida. Sin embargo, Cádiz se quejaría repetidamente, tratando de arrebatar el control político del Consulado de manos de Sevilla ${ }^{52}$.

\section{El Último PASO}

El acto final del drama del traslado del Consulado a Cádiz ocurrió en circunstancias muy diferentes. Mientras Patiño gobernó, había favorecido al Consulado de varias formas, pero a cambio esperaba que satisficiera sus necesidades, especialmente con préstamos oportunos y donativos. El acuerdo de Utrecht y los subsecuentes tratados de Bubb habían obligado a España a mantener su histórico sistema comercial. Las capitulaciones españolas para poner término a la Guerra de la Cuádruple Alianza afirmaban esa obligación, y el Real Proyecto de 1720 la codificaba. Dadas estas limitaciones, Patiño no tenía más remedio que actuar por medio del Consulado. Y eso hizo con habilidad considerable. Del gremio, extrajo donativos periódicos, y en 1732, este accedió a administrar un impuesto del cuatro

51. Heredia Herrera, A.: «Las elecciones en el Consulado de Cargadores a Indias: nuevas perspectivas sobre la rivalidad Sevilla-Cádiz», en Primeras Jornadas de Andalucía y América, I, 1982, pp. 169-79; CRespo, A.: La Casa, p. 131.

52. Consulta, Consejo de Indias, 9 de diciembre de 1743, AGI, IG, leg. 2302. 
por ciento sobre plata, oro y grana fina importada de las colonias para mantener el sistema de guarda costas que patrullaban las aguas americanas. Es más, en las periódicas ferias que el Consulado estaba obligado a mantener, tenía que tolerar los molestos y dañinos navíos de permiso permitidos a los ingleses por los tratados existentes. Por otra parte, Patiño permitía al Consulado manejar sus asuntos interiores con poca supervisión, incluso la administración de los gravámenes sobre el comercio como compensación por los préstamos a la corona ${ }^{53}$. Quizás y más significativo, por decreto de septiembre 23 de 1729, hasta aseguró el derecho a definir sus reglas de membresía para proteger su dominante oligarquía sevillana, quienes entonces se hallaban bajo amenaza por parte de los jenízaros, los hijos naturalizados de mercaderes extranjeros ${ }^{54}$. Se debe notar, sin embargo, que el establecimiento de la Real Compañía Guipuzcoana de Caracas en 1728 por Patiño, hecho bajo fuertes protestas del Consulado, demostró que su influencia sobre él era mucho menos que absoluta ${ }^{55}$. La armonía entre la corona y el gremio reinó hasta la muerte de Patiño en 1736. El último paso en el traslado del Consulado de Sevilla a Cádiz resultaría de las nuevas realidades surgidas para entonces y los explosivos eventos a que darían lugar.

El período que siguió a la muerte de Patiño y precedió la emergencia de Ensenada en 1743 sentó las bases para la política del desenlace final. Estos años vieron la sucesión de hombres en la Secretaría de Marina e Indias que asumían el poder pero brevemente, pero que sin embargo eran individuos de substancia. Estos incluyeron al marqués de Torrenueva (1736-1739), José de la Quintana (1739-1741), y el bien conocido José del Campillo y Cossío (1741-1743) ${ }^{56}$. Lo que los distinguió era su voluntad de desafiar la situación privilegiada del Consulado y, eventualmente, la dominación de la élite sevillana en él. Aunque habían surgido bajo Patiño, estos magistrados parecían bien inclinados a cuestionar la herencia institucional que habían recibido del gran ministro.

La primera brecha en el compacto entre el Consulado y Madrid surgió en 1737 de una fuerte disputa sobre un donativo que la corona había solicitado del Consulado. Balanceándose al borde de la bancarrota, entre otras cosas debido a la ambiciosa agenda de construcción naviera heredada de Patiño y a

53. Kuethe, A. J. y Andrien, K. J.: The Spanish Atlantic World, cap. 3.

54. Ruiz Rivera, J.: El Consulado de Cádiz: matrícula de comerciantes, 1730-1823. Cádiz, 1988, p. 21.

55. Garate Ojanguren, M.: La Real Compañia Guipuzcoana de Caracas. San Sebastián, 1990, cap. 5 .

56. Para antecedentes y atributos de estos hombres, véase Kuethe, A. J. y Andrien, K. J.: The Spanish Atlantic World, pp. 135-37. 
la extravagante construcción palaciega avanzada por Sus Majestades, la corona, a través del secretario de Hacienda marqués de Torrenueva, pidió un donativo del quince por ciento de las ganancias de la flota de Manuel López Pintado y de los azogues que regresaban de Veracruz, valorados en 17.000.000 de pesos ${ }^{57}$. Dicha suma vendría a ser en la actualidad aproximadamente 2.250 .000 pesos, pero porque incluía gravámenes existentes, el donativo en sí vendría a ser cerca del seis por ciento, algo poco más de un millón de pesos, suma que cuadraba bien con la cantidad que Patiño había sacado de costumbre.

El gremio, sin embargo, no estaba de ánimo generoso. Por una parte, estaba disgustado por una reciente revaluación del peso plata de dieciséis a veinte reales, que aducía afectaba adversamente los contratos que había negociado antes, bajo los antiguos valores, y aumentó sus impuestos. Por otra parte, uno sospecha que el Consulado se sentía menos intimidado por el liderato actual que lo había estado bajo Patiño. Respondió a la demanda con la exigua oferta de $250.000^{58}$.

En tanto que las diferencias en esta instancia eran considerables, el regateo entre el gremio y la corona era parte del acostumbrado juego político. Lo que era novedoso era la áspera e impaciente respuesta de Torrenueva, quien no estaba de ánimo para largas negociaciones y quien parecía ansioso de confrontar al gremio. Esta nueva mentalidad de seguro se derivaba al menos en parte de la escena internacional en la que España se acercaba más y más a una guerra con Gran Bretaña debido a intereses conflictivos del comercio americano. A otro nivel, el final de la obligación diplomática de España de treinta años de acomodar el odiado Asiento de Negros se acercaba y con ello la oportunidad de revaluar el sistema colonial comercial existente. De cierto, en la disputa diplomática que acabaría en guerra, Madrid había unilateralmente declarado el fin del Asiento ${ }^{59}$.

De inmediato, Torrenueva convocó en su hogar una junta de cuatro ministros y tres teólogos para evaluar la conducta del Consulado. La presencia teológica anticipaba la necesidad de justificar moralmente los castigos que esperaba dar al gremio, precaución, se debe notar, ique fue tomada aun antes de que alguna falta o deficiencia fuese actualmente establecida! Predeciblemente, Villanueva, apoyado

57. La feria de Jalapa había resultado extraordinariamente fructífera porque las autoridades españolas se las ingeniaron para excluir el navío de permiso británico. WALKER, G. J.: Spanish Politics and Imperial Trade, 1700-1789. Bloomington, 1979, pp. 173-77, 188-92.

58. He tratado esta controversia con más profundidad en «El fin del monopolio. Los Borbones y el consulado andaluz», en Vila Vilar, E. y Kuethe, A. J.: Relaciones de poder, pp. 43-45, y con Lowell Blaisdell en «French Influence and the Origins of the Bourbon Colonial Reorganization», The Hispanic American Historical Review, 71, 1991, pp. 579-607.

59. La fecha exacta del fin del Asiento no estaba clara porque los años de guerra no contaban hacía los treinta. 
por su junta, concluyó que el Consulado había en efecto ocultado bienes y efectivo del recaudador de impuestos en los navíos de regreso, con un valor de cuatro millones de pesos. Además de la suma solicitada originalmente, la corona impuso la cuantiosa multa del cinco por ciento del oro y la plata por la cual condescendió a dar su perdón ${ }^{60}$.

La investigación no finalizó en ese punto, sin embargo, sugiriendo que la corona buscaba más que una infusión provisional para su tesoro. El sucesor de Torrenueva, José de la Quintana, hizo medir los navíos del Consulado anclados en el puerto de Cádiz. Esta investigación reveló que su tamaño había sido grandemente subestimado, facilitando así ocultar carga no declarada ${ }^{61}$. Es más, un estudio de los libros del Consulado reveló que los registros de los derechos de Lonja e Infantes, impuestos que administraba para pagarse sus préstamos a la corona, estaban en terribles condiciones y con grandes vacíos en la insuficiente documentación que contenían ${ }^{62}$. Las tensiones aumentaron aún más cuando en 1739 Madrid se halló obligada a suspender los pagos de sus deudas, pocos meses antes del sorprendente ataque inglés a Portobelo, que dio principio de la Guerra del Asiento ${ }^{63}$. Estos acontecimientos abrieron la puerta a una serie de medidas transformativas limitando la autonomía del Consulado. De este proceso resultó la extracción del gremio de las manos de Sevilla, completando así el traslado que había comenzado en 1717.

José del Campillo y Cossío, conocido por su obra reformista, Nuevo sistema económico para América, que incluía un argumento para la desregulación del comercio colonial, introdujo un nuevo arreglo el 13 de noviembre de 1741 que imponía al gremio normas estrictas de contabilidad que serían auditadas por la Casa de Contratación bajo la supervisión del Consejo de Indias ${ }^{64}$. Al año siguiente, Campillo estableció un nuevo sistema para asegurar la medida exacta de los barcos y navíos que iban a América. ${ }^{65}$. Y en abril de 1742 abrió la entrada al Consulado, rompiendo así el control de reclutamiento de la élite que había monopolizado la membresía desde la concesión de Patiño de 1729, y, además, quitó la supervisión

60. Resolución a la consulta de la Junta de Ministros y Teólogos, Madrid, 27 de octubre de 1737, AGI, IG, leg. 2300.

61. García-Baquero González, A.: Cádiz y el Atlántico (1717-1778), I. Sevilla, 1976, pp. 217-19.

62. Reales órdenes, Madrid, 30 de noviembre y 22 de diciembre de 1739, 8 de marzo y 27 de septiembre de 1740, AGI, IG, leg. 2324.

63. Fernández de Albaladejo, P.: «El decreto de suspensión de pagos de 1739: análisis e implicaciones", Moneda y crédito, Madrid, núm. 142, 1977, pp. 51-85.

64. AGI, IG, leg. 2302 y Consulados, leg. 52A.

65. Real orden, San Ildefonso, 19 de septiembre de 1742, AGS, Marina, leg. 767. 
de este proviso de manos de la Casa, colocándolo bajo la vía reservada ${ }^{66}$. El peso de estas medidas redujo al gremio mercantil, antes tan autónomo, a un control real mucho más fuerte. El marqués de la Ensenada, quien sucedió a Campillo tras su prematura muerte en abril de 1743, entonces llevó esta serie poco sistemática de reformas a su conclusión con la decisiva Real Orden de diciembre 17 de 1743, confirmada por la Real Cédula de 1 de febrero ${ }^{67}$.

Este acto de Ensenada le quitó a Sevilla el control del liderato del Consulado, poniendo fin a su dominio del gremio y marcando el paso final del largo y complicado proceso del traslado. El asunto había sido primero referido al Consejo de Indias, que en consulta de 9 de diciembre dio la solución que Ensenada impuso. Su decreto reducía los electores de Sevilla de veinte a diez, poniéndola a la par de Cádiz. Dividió los restantes diez entre los satélites gaditanos de Puerto de Santa María (4), Sanlúcar de Barrameda (3), y Jerez de la Frontera (3). Reuniéndose anualmente en Sanlúcar, los delegados elegirían un cónsul al año, alternando entre Sevilla, Cádiz y los tres satélites. El cónsul de mayor antigüedad sería automáticamente prior $^{68}$. Aparte de humillar a Sevilla, se debe notar que el paso absolutista de Ensenada de reasignar los electores del consulado respondía a nuevas realidades económicas y demográficas, ya que desde el compromiso de Patiño de 1726 Cádiz y sus alrededores habían continuado aflorando ${ }^{69}$. En efecto, él reemplazó una élite con otra, esto es, la élite arraigada de Sevilla con la clase mercantil de Cádiz que iba en aumento, hombres que probablemente deberían más a Madrid y las nuevas direcciones que tanteaba para llegar al estado absolutista ilustrado.

Finalmente, procesos criminales fueron iniciados contra los cónsules y los priores de los años 1728 a 1743. Mantenido por Ensenada hasta los años cincuenta, este proceso llevó a la confiscación y venta de las propiedades de los acusados como el medio de cubrir los supuestos déficits de Lonja e Infantes ${ }^{70}$. A parte de cualesquiera méritos fiscales que estos castigos puedan haber tenido, iban claramente encaminados a debilitar el poder económico de la antigua élite. Con esta serie de pasos, el dominio de Sevilla llegó a su fin. El Consulado pertenecía a Cádiz.

Estas reformas tuvieron lugar durante tiempos de guerra, cuando el Consulado, como la tradicional fuente de socorro para las reales finanzas, vio su importancia disminuida por la intrusión de la Real Compañía Guipuzcoana de Caracas.

66. Hay una copia de la cédula en Ruiz Rivera, J.: El Consulado de Cádiz, p. 21.

67. AGI, IG, leg. 2302. Ensenada también fue secretario de Hacienda y de Guerra.

68. Ibidem. Al principio, Sevilla se negó a participar bajo el nuevo reglamento, pero eventualmente tuvo que ceder. Heredia Herrera, A.: Sevilla y los hombres, p. 87.

69. Bustos Rodríguez, M.: Cádiz en el sistema atlántico, pp. 73 y 79.

70. Expediente, proceso de Antonio Espinosa, 1751-1753, AGI, IG, leg. 2044. 
Proveyendo navíos y préstamos, los servicios de la compañía caraqueña resultaron de importancia vital para mantener el esfuerzo de Madrid para aumentar sus defensas en el Caribe y, en particular las de Nueva Granada, que exitosamente repelieron la invasión inglesa de Cartagena en 1741, así como la amenaza a Panamá al año siguiente. El Consulado también proveyó préstamos y donativos en varias ocasiones, pero ya no era la única fuente disponible ${ }^{71}$. Al tiempo que el monopolio sevillano de socorro monetario se debilitaba, así también lo hizo su poder político.

Es más, el establecimiento de la Compañía de La Habana en 1740, la mitad de cuyas acciones estaban en manos americanas, proporcionó los medios para extraer tabaco cubano para la Real Fábrica en Sevilla y aseguró un agresivo régimen de construcción de navíos en el astillero habanero para la adorada armada de Ensenada $^{72}$. Estos pasos para debilitar el monopolio del Consulado eran presagio de la amplia desregulación comercial bajo Carlos III.

\section{Conclusión}

El decisivo avance que culminó bajo Ensenada había sido precedido por un largo y complicado proceso testigo de las nuevas políticas borbonas manifestadas por Alberoni y Riperdá, el tradicional enfoque de Grimaldo y Miraval y la moderación de Patiño, situado más o menos entre ambos. Mirando hacia atrás se puede percibir una evolución algo irregular hacia el absolutismo borbón personificado por el marqués de la Ensenada y sus predecesores inmediatos. Las abruptas acciones de Alberoni y más tarde de Riperdá fueron una áspera advertencia del nuevo tono que el absolutismo español asumiría a medida que el siglo avanzaba. La reacción contra el advenedizo italiano tras su destierro en 1719 volvió la política bajo el conservador Grimaldo y su secuaz Miraval a su curso normal. La última esperanza de Sevilla desapareció con la muerte del Rey Luis. El duro pero práctico Patiño halló la forma precisa para cerrar la brecha entre Sevilla y Cádiz. Y sobrevivió hasta su muerte. Mejor plasmado en la dura mano del ilustrado Ensenada, el nuevo absolutismo que resurgió durante los decisivos años de 1737 a 1743 completó el traslado que había comenzado más de veintiséis años antes. Esta legislación transformadora tuvo lugar poco a poco y no en un solo paquete reformador, tomando forma en respuesta a una percibida mala conducta que debía

71. Kuethe, A. J. y Andrien, K. J.: The Spanish Atlantic World, pp. 142-45.

72. McNeIll, J. R.: Atlantic Empires of France and Spain: Louisbourg and Havana, 17001763. Chapel Hill, 1985, pp. 119-22; IngLIs, G. D.: «The Spanish Naval Shipyard at Havana in the Eighteenth Century", en New Aspects of Naval History: selected Papers from the 5th Naval History Symposium. Baltimore, 1985, pp. 51-52. 
ser corregida, y por último, castigada. Era presagio de lo poco sistemático de los adelantos, cuidadosos pero audaces, observados durante el reino de Carlos III a medida que él y sus ministros transformaban el gobierno del imperio americano.

\section{Bibliografía}

Béthencourt Massieu, A.: Patiño en la política internacional de Felipe V. Valladolid, 1954.

Burkholder, M. A.: Biographical Dictionary of Councilors of the Indies, 1717-1808. Nueva York, 1986.

Bustos Rodríguez, M.: Cádiz en el sistema atlántico: la ciudad, sus comerciantes y la actividad mercantil (1650-1830). Cádiz, 2005.

Bustos Rodríguez, M.: «El Consulado de Indias en Cádiz y sus hombres: el cambio de relaciones entre la institución y el cabildo municipal», en Acosta Rodríguez, A, GonzÁlez Rodríguez, A, y Vila Vilar, E. (redactores): La Casa de la Contratación y la navegación entre España y las Indias. Sevilla, 2003, pp. 915-16.

Castellano, J. L.: Gobierno y poder en la España del siglo XVIII. Granada, 2006.

Castro, A. de: Vida del Almirante D. Andrés de Pes, ministro de marina. Cádiz, 1879.

Castro, C.: A la sombra de Felipe V: José Grimaldo, ministro responsable (1703-1726). Madrid, 2004.

Crespo Solana, A.: La Casa de la Contratación y la Intendencia General de Marina en Cádiz. Cádiz, 1996.

Escudero, J. A.: Los orígenes del Consejo de Ministros en España, I. Madrid, 1979.

Fernández de Albaladejo, P.: «El decreto de suspensión de pagos de 1739: análisis e implicaciones", Moneda y crédito, 142, 1977, pp. 51-85.

Fernández Duro, C.: Armada española desde la unión de los Reinos de Castilla y Aragón, IV. Madrid, 1972-1973.

Gárate Ojanguren, M.: La Real Compañía Guipuzcoana de Caracas. San Sebastián, 1990.

García-Baquero González, A.: Cádiz y el Atlántico (1717-1778), I. Sevilla, 1976.

GARCÍA CÁRCEL, R.: Felipe $V$ y los españoles: una visión periférica del problema de España. Barcelona, 2002, p. 152.

García Fuentes, L.: El comercio español con América, 1650-1700. Sevilla, 1980, pp. 63-65.

GIRARD, A.: La rivalité commerciale et maritime entre Séville et Cadix jusqu'a la fin $d u$ XVIII siècle. París y Burdeos, 1932.

Heredia Herrera, A.: «Las elecciones en el Consulado de Cargadores a Indias: nuevas perspectivas sobre la rivalidad Sevilla-Cádiz», en Primeras Jornadas de Andalucía y América, I, 1982, pp. 169-79.

Heredia Herrera, A.: Sevilla y los hombres del comercio (1700-1800). Sevilla, 1989, pp. 127-28.

Inglis, G. D.: «The Spanish Naval Shipyard at Havana in the Eighteenth Century», en New Aspects of Naval History: Selected Papers from the $5^{\text {th }}$ Naval History Symposium, Baltimore, 1985, pp. 51-52. 
Kamen, H.: Philip V of Spain: The King who Reigned Twice. New Haven, 2001.

Kuethe, A. J.: «La política exterior de Felipe V y el primer reformismo», en Lavallé, B. (redactor): El primer siglo XVIII en Hispanoamérica. Toulouse, 2012, pp. 30-32.

Kuethe, A. J.: «El fin del monopolio: Los Borbones y el consulado andaluz», en VILA VILAR, E. y KueTHE, A. J. (redactores): Relaciones de poder y comercio colonial: nuevas perspectivas. Sevilla, 1999, pp. 35-66.

Kuethe, A. J.: «Traslado del Consulado de Sevilla a Cádiz: nuevas perspectivas», en VILA VILAR, E. y Kuethe, A. J. (redactores): Relaciones de poder y comercio colonial: nuevas perspectivas. Sevilla, 1999, pp. 67-82.

Kuethe, A. J. y Andrien, K. J.: The Spanish Atlantic World in the Eighteenth Century: War and the Bourbon Reforms, 1713-1796. Cambridge, 2014, pp. 57-61.

Kuethe, A. J. y Blaisdell, L.: «French Influence and the Origins of the Bourbon Colonial Reorganization», The Hispanic American Historical Review, 71, 1991, pp. 579-607.

LyNCH, J.: Bourbon Spain, 1700-1808. Oxford, 1989.

McNeILl, J. R.: Atlantic Empires of France and Spain: Louisbourg and Havana, 17001763. Chapel Hill, 1985.

Pérez-Mallaína Bueno, P. E.: La política española en el Atlántico, 1700-1715. Sevilla, 1982.

Pietschmann, H.: Las reformas borbónicas y el sistema de intendencias en Nueva España: un estudio político administrativo, trans. por Rolf Roland Meyer Misteli. México, 1996.

Ravina Martín, M. (intro.): El pleito Cádiz Sevilla por la Casa de la Contratación: memorial de FCO Manuel Herrera 1726..., Cádiz, 1984.

Ruiz rivera, J.: El Consulado de Cádiz: matrícula de comerciantes, 1730-1823. Cádiz, 1988.

Walker, G. J.: Spanish Politics and Imperial Trade, 1700-1789. Bloomington, 1979. 